\title{
Oscillatory fluid flow elicits changes in morphology, cytoskeleton and integrin-associated molecules in MLO-Y4 cells, but not in MC3T3-E1 cells
}

\author{
Huiyun Xu, Jian Zhang, Jiawei Wu, Ying Guan, Yuanyuan Weng, Peng Shang ${ }^{1}$ \\ ${ }^{1}$ Key Laboratory for Space Biosciences \& Biotechnology, School of Life Sciences, Northwestern Polytechnical University,
}

\begin{abstract}
Interstitial fluid flow stress is one of the most important mechanical stimulations of bone cells under physiological conditions. Osteocytes and osteoblasts act as primary mechanosensors within bones, and in vitro are able to respond to fluid shear stress, both morphologically and functionally. However, there is little information about the response of integrin-associated molecules using both osteoblasts and osteocytes. In this study, we investigated the changes in response to 2 hours of oscillatory fluid flow stress in the MLO-Y4 osteocyte-like cell line and the MC3T3-E1 osteoblast-like cell line. MLO-Y4 cells exhibited a significant increase in the expression of integrin-associated molecules, including OPN, CD44, vinculin and integrin avß3. However, there was no or limited increase observed in MC3T3-E1 osteoblast-like cells. Cell area and fiber stress formation were also markedly promoted by fluid flow only in MLO-Y4 cells. But the numbers of processes per cell remain unaffected in both cell lines.
\end{abstract}

Key words: Cytoskeleton, fluid flow stress, integrin-associated molecules, MC3T3-E1 osteoblast-like cell line, MLO-Y4 osteocyte-like cell line

\section{INTRODUCTION}

Bone cells respond to mechanical stimulations physiologically. This is one of the causes of bone remolding. In vivo, interstitial fluid flow stress in the lacunae-canaliculi network is one of the main mechanical stimulations on bone cells (Swan et al., 2003). Given that the mechanical loading of bone generates dynamic fluid flow stress, oscillatory fluid flow (OFF) is considered a better model of the physiological conditions for in vitro experimentation than unidirectional fluid flow (including steady and pulsatile) (Ponik et al., 2007). The magnitude of fluid flow stress in bone tissue is thought to be between 0.8 and 3.0 $\mathrm{Pa}$ in vivo (Weinbaum et al., 1994). In vitro, primary mechanosensors, osteocytes and osteoblasts have been used to investigate the morphological and functional responses to fluid shear stresses (Barron et al., 2010; Letechipia et al., 2010). As well, in the past twenty years there have been many important developments in mechanotransduction (Reich and Frangos, 1993),(Jiang and Cheng, 2001). Many groups have compared the differences in calcium response (Kamioka et al., 2006; Murshid et al., 2007), cytoskeleton (Ponik et al., 2007), NO and PGE2 secretion (McGarry et al., 2005; Reilly et al., 2003) in osteocytes and osteoblasts under fluid stress. Klein-Nulend $J$ et al, have shown that pulsating fluid flow induces higher NO and PGE2 production in osteocytes than in osteoblasts (Ajubi et al., 1996; Klein-Nulend et al., 1997; Klein-Nulend et al., 1995; Westbroek et al., 2000). Pavalko et al, have shown that oscillatory and unidirectional fluid flow profiles elicit different cytoskeleton responses of osteocytes and osteoblasts (Ponik et al., 2007).

The cytoskeleton is considered to be the major factor influencing cellular morphology and biomechanical response in bone cells (Alenghat and Ingber, 2002). Integrins can link the cellular cytoskeletal network to the extracellular matrix (ECM)
(Geiger et al., 2001). Together with other associated molecules, integrins participate in typical mechanochemical signal transduction. However, the response of integrin-associated molecules to fluid flow using both osteoblasts and osteocytes has rarely been evaluated.

Under different external mechanical conditions, bone cells exhibit different cell morphologies (van Hove et al., 2009; Vatsa et al., 2008), which in turn determines cell function. Aviral Vatsa et al. have reported the significant differences in the 3D morphology of single osteocyte in fibulae and calvariae bones of adult mice, which is likely to be an adaptation to the difference in physiological mechanical loading patterns in these bones (Vatsa et al., 2008). However, cell area response under fluid flow in osteoblasts and osteocytes has not yet been investigated.

In this study, MLO-Y4 osteocyte-like cells and MC3T3-E1 osteoblast-like cells were subjected to $1 \mathrm{~Pa}\left(10\right.$ dynes $\left./ \mathrm{cm}^{2}\right)$ of oscillatory fluid flow stimulation for 2 hours (h). The aim of this study was to compare the responses of the two cell lines to fluid flow stress in terms of morphology, cytoskeleton and expression of integrin-associated genes.

\section{MATERIALS AND METHODS}

\section{1 cell culture:}

The MLO-Y4 cell line was donated by Professor Lynda Bonewald (University of Missouri-Kansas City) (Bonewald, 1999). The cells were cultured in $\alpha$-MEM (GIBCO) with $2.5 \%$ fetal bovine serum (FBS) and $2.5 \%$ calf serum including $1 \%$ penicillin/streptomycin. The osteoblast-like cell line MC3T3-E1 was purchased from the Cell Bank of the Chinese Academy of Medical Sciences, and the cells were cultured in $\alpha$-MEM with $10 \%$ FBS. 


\section{2 fluid flow experiment}

MLO-Y4 and MC3T3-E1 cells were plated on glass slides (2.0 $\mathrm{cm} \times 6.0 \mathrm{~cm})$ at the density of $2.2 \times 10^{6}$ per slide. The cells were then incubated in a humidified atmosphere with $5 \% \mathrm{CO}_{2}$, at $37^{\circ} \mathrm{C}$, for $24 \mathrm{~h}$. The slides were then placed in a parallel-plate chamber as described by C.R. Jacobs (Jacobs et al., 1998). Oscillatory fluid flow stress was applied to the cells (group E) for $2 \mathrm{~h}$, at a frequency of $1 \mathrm{~Hz}$. The peak shear stress was $1.0 \mathrm{~Pa}$ (10 dynes $/ \mathrm{cm}^{2}$ ). Static control cells (group C) were cultured in the same incubator at $37^{\circ} \mathrm{C}$ with $5 \% \mathrm{CO}_{2}$.

\subsection{Haematoxylin-eosin (HE) staining}

Cells on glass slides were collected and washed twice with phosphate-buffered saline (PBS), pH 7.4 and fixed in $0.5 \%$ glutaraldehyde solution in PBS for $10 \mathrm{~min}$. The slides were incubated in $0.5 \%$ haematoxylin for $10 \mathrm{~min}$ and $0.5 \%$ eosin for $7 \mathrm{~min}$, respectively. The cells were then dehydrated by a series of ethanol solutions with increasing concentrations, made transparent with dimethylbenzene. Cells were observed under microscope and images were taken, then cells were zoned along cell contour on the images, the cell area was analyzed by simple PCI software (Compix, USA). As well, the number of processes/cell (the number of dendrite processes per cell) was counted based on the images. Five random fields of vision were observed and images were taken, and more than 20 cells were detected in one image. Statistical analysis was done by Graphpad Prism software (La Jolla, CA). The independent experiments were repeated three times.

\subsection{Confocal imaging}

After washing with PBS for three minutes twice, cells were fixed by the addition of $0.5 \%$ glutaraldehyde solution in PBS for ten minutes at room temperature. The cells were then permeabilized using PBS containing 0.1\% Triton X-100 solution and blocked with blocking buffer (PBS+0.1\% Tween $+1 \%$ serum) for $10 \mathrm{~min}$. Cells were incubated overnight in rhodamine labeled-phalloidin (1:40, Invitrogen) or in the antibody $\alpha$-tubulin (1:2000, Sigma). After being washed by TBS with $0.1 \%$ Triton, the cells were incubated for $1 \mathrm{~h}$ in FITC labeled (1:10, KPL) secondary antibody in order to stain the tubulin. Then the cells were washed and examined using confocal microscopy (Leica TCS SP5, Germany).

\subsection{Quantitative real-time PCR analysis}

The total RNA was extracted using Trizol (Invitrogen). Reverse transcription was accomplished based on the protocol provided with the kit (TaKaRa). Primers were designed and synthesized (Sangon) based on the sequence of genes available

\section{TABLE I}

Primer sequences

\begin{tabular}{|c|c|c|c|}
\hline Gene name & Primer sequences & Annealing temperature $\left({ }^{\circ} \mathrm{C}\right)$ & Amplication length (bp) \\
\hline \multirow{2}{*}{ Cox-2 } & F5GGTCTGGTGCCTGGTCTGATGAT3 & \multirow{2}{*}{55} & \multirow{2}{*}{122} \\
\hline & R5CTGCTGGTTTGGAATAGTTGCTC3 & & \\
\hline \multirow{2}{*}{ Runx2 } & F5TGCACCTACCAGCCTCACCATAC3 & \multirow{2}{*}{57} & \multirow{2}{*}{105} \\
\hline & R5GACAGCGACTTCATTCGACTTCC3 & & \\
\hline \multirow{2}{*}{ E11/gp38 } & F5CGACCAGTTTCTAACACCTGCCTTCT3 & \multirow{2}{*}{60} & \multirow{2}{*}{164} \\
\hline & R5CTGTCCCAGCAACACTGAGTCCC3 & & \\
\hline \multirow{2}{*}{$\beta$-actin } & F5AACAGTCCGCCTAGAAGCAC3 & \multirow{2}{*}{55} & \multirow{2}{*}{281} \\
\hline & R5CGTTGACATCCGTAAAGACC3 & & \\
\hline \multirow{2}{*}{$\alpha$-tubulin } & F5TGGCAAGTATGTCCCTCG3 & \multirow[b]{2}{*}{55} & \multirow{2}{*}{450} \\
\hline & R5AGCCTCGTTGTCGATGCAGTAG3 & & \\
\hline \multirow{2}{*}{ integrin $\alpha_{v}$} & F5GAATGGCGAAGGAAACTCTGAAA3 & \multirow{2}{*}{51} & \multirow{2}{*}{157} \\
\hline & R5ATAAACTGAGACTGCTGGGTGCT3 & & \\
\hline \multirow{2}{*}{ integrin $\beta_{3}$} & F5CCACCTTCACCAATATCAC3 & \multirow{2}{*}{55} & \multirow{2}{*}{125} \\
\hline & R5CCAAATCCCACCCATACAC3 & & \\
\hline \multirow{2}{*}{ OPN } & F5 TTCACTCCAATCGTCCCTAC3 & \multirow{2}{*}{56} & \multirow{2}{*}{235} \\
\hline & R5 TGCCCTTTCCGTTGTTGTC3 & & \\
\hline \multirow{2}{*}{ CD44 } & F5 GGATTCATCCCAACGCTAT3 & \multirow{2}{*}{56} & \multirow{2}{*}{216} \\
\hline & R5 ACTCGCCCTTCTTGCTGT3 & & \\
\hline \multirow{2}{*}{ vinculin } & F5 ATGACATCCTCCGCTCCCTT 3 & \multirow{2}{*}{55} & \multirow{2}{*}{214} \\
\hline & R5 GCCTGTTCAATCTTGCCCTC 3 & & \\
\hline \multirow{2}{*}{$18 \mathrm{~S}$} & F5AATCAGGGTTCGATTCCGGA3 & \multirow{2}{*}{55} & \multirow{2}{*}{257} \\
\hline & R5 CCAAGATCCAACTACGAGCT3 & & \\
\hline
\end{tabular}


in GenBank. These primer sequences are shown in Table 1. SYBR Green real-time relative quantitative RT-PCR analysis was performed with SYBR Premix Ex TaqTM based on the manufacturer's protocol (TaKaRa) on a MJ Research (BioRad, Hercules, CA, USA), and each sample was measured in triplicate, and normalized to $18 \mathrm{~S}$. The Livak method was used to estimate the relative changes in gene expression (Livak and Schimittgen, 2001).

\subsection{Western blotting}

Cells were harvested in a lysis buffer, and equal amount of cellular proteins was subjected to SDS-PAGE (10\%) separation. Proteins were transferred to NC membranes, and blots were probed with antibodies of $\beta$-actin (1:2000, Sigma), $\alpha$-tubulin (1:1000, Calbiochem) and vinculin (1:1500, Sigma), respectively. GAPDH (glyseraldehyde-3-phosphate dehydrogenase, 1:2000, Calbiochem) was as the internal control protein. Blots were washed 5 times, $5 \mathrm{~min} /$ time, with TBST (Tris-buffered saline with $0.05 \%$ tween-20) and incubated with HRP (Horse Radish Peroxidase)-labeled secondary antibody (1:2000, CWBIO) for $2 \mathrm{~h}$. The membranes were washed as described above, and the bands were detected by enhanced chemiluminescence. Then the bands were scanned by Get Doc XR system, then quantified and analyzed by Quantity One software.

\subsection{Statistical analysis}

Statistical analysis was performed using GraphPad Prism 5 statistics software (San Diego, USA). All data were presented as mean value \pm standard deviation (SD). The one way ANOVA and t-test were used for statistical analysis. $P<0.05$ was considered statistically significant.

\section{RESULTS}

\subsection{Cell morphology and cytoskeleton arrangement}

After application of OFF for $2 \mathrm{~h}$, the cell area of the MLO-Y4 cells increased by approximately $65.6 \%$. However, there was no significant change in the cell area of the MC3T3-E1 cells (Fig. 1a and $1 \mathrm{~b}$ ). The numbers of processes per cell in both cells were not influenced by the fluid flow stress (Fig. 2).

After OFF stimulation, expressions of $\beta$-actin (Fig. 3a and 3c) and $\alpha$-tubulin (Fig. $3 b$ and $3 d$ ) were both clearly enhanced in MLO-Y4 cells. As well, the formation of stress fiber was promoted. On the other hand, in MC3T3-E1 cells, there was not obvious difference compared to that of control.

\subsection{Integrin-associated molecules expression at mRNA level}

Quantitative real-time PCR was carried out to detect gene expression at mRNA level. From Fig 4, it can be seen that some genes were dramatically changed in the MLO-Y4 cells. Among them, integrin $\alpha \mathrm{v}$ increased approximately 2.5 fold in the cells subjected to OFF compared to the static control cells. Integrin $\beta 3$ also increased approximately 13 fold and vinculin increased 2.5 fold. However, in MC3T3-E1 cells, the expressions of integrin $\alpha v, \beta 3$ and vinculin were not obviously changed by fluid flow treatment.

As well, E11/gp38 increased about 7.5 fold in MLO-Y4 cells, while it approximately doubled in MC3T3-E1 cells. In MLO-Y4 cells cox-2 and Runx2 expression increased approximately 3.9 fold and 6.7 fold respectively, while in MC3T3-E1 cells, there was no obvious change to cox-2, and Runx2 increased 2.4 fold. OPN and CD44 expression approximately doubled in MLO-Y4 cells, while in MC3T3-E1
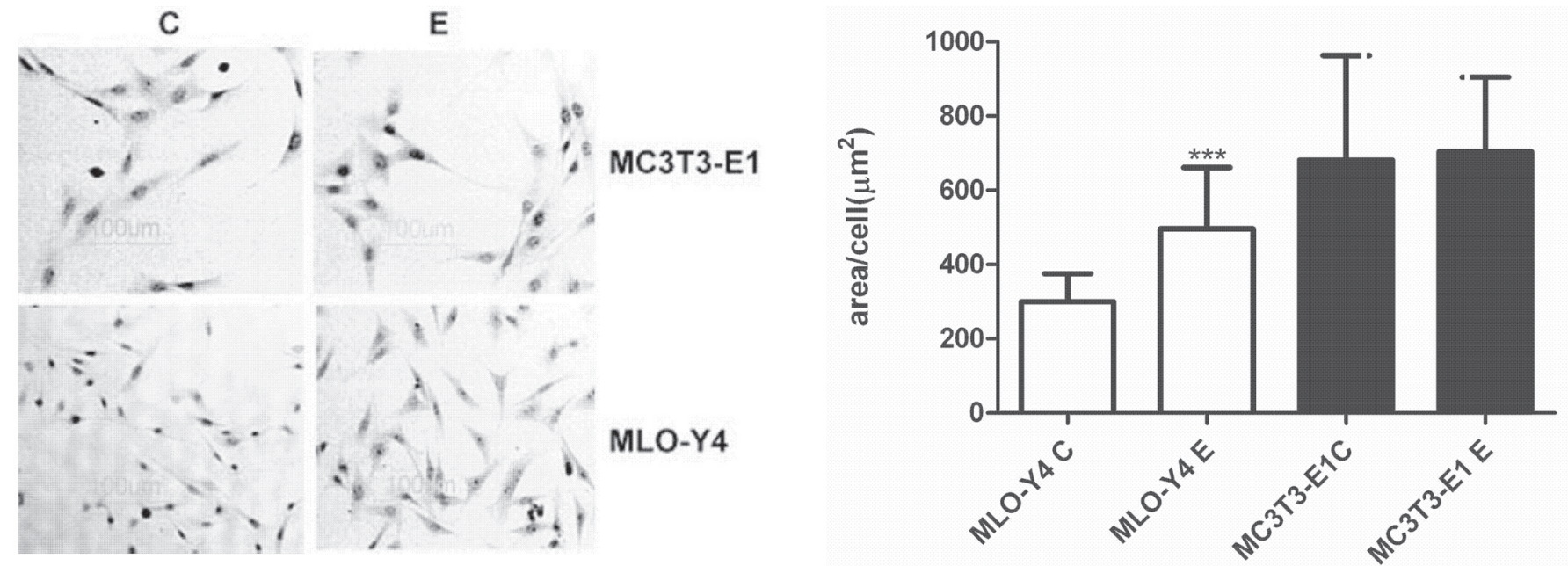

Fig. 1. After subjected to $2 \mathrm{~h}$ of oscillatory fluid flow stress (OFF), cells were collected, fixed and stained by haematoxylin and eosin, then observed under microscope and images were taken (a). Cells were zoned along the cell contour; the cell area was analyzed using simple $\mathrm{PCl}$ software. The cell area of MLO-Y4 cells increased by approximately $65.6 \%$, however there was no significant change in the cell area of the MC3T3-E1 cells (b). Statistical analysis was performed using GraphPad Prism 5 statistics software (San Diego, USA). The bar is $100 \mu \mathrm{m}$. $\mathrm{C}$ : control, E: $2 \mathrm{~h}$ of oscillatory fluid flow. ${ }^{* * *} P<0.001$ 
cells OPN and CD44 were not markedly influenced by the $2 \mathrm{~h}$ of fluid flow.

Real-time PCR results showed cytoskeleton molecule $\beta$-actin expression increased 1.8 fold, $\alpha$-tubulin increased 3.9 fold in MLO-Y4 cells, while in MC3T3-E1 cells the changes of $\beta$-actin and $\alpha$-tubulin were not obvious.

\subsection{Western blotting}

From Fig $5 a$ and $5 b$, it can be seen that $\alpha$-tubulin increased about 1.7 fold in the MLO-Y4 cells and 1.3 fold in MC3T3-E1 cells after $2 \mathrm{~h}$ of OFF. $\beta$-actin increased less than 1.3 fold in both of the two cells. Vinculin increased about 1.7 fold in MLO-Y4 cells, while there was not obvious change in MC3T3-E1 cells.

\section{DISCUSSIONS}

Under physiological condition, bone cells could response to mechanical stimulation and regulate the balance between bone formation and resorption. Scientists have investigated some morphological and functional changes after mechanical stimulation (such as fluid flow) in osteoblasts. In recent years there has been greater attention in this field on osteocytes. As two well-established cell models representing osteoblasts and osteocytes, MC3T3-E1 and MLO-Y4 cells have been used in many studies. Consequently, it is important to compare the difference between the two kinds of representative bone cells in the response to given fluid flow shear stress, such as morphology, structure and expression of related genes. Which are more sensitive to fluid flow, osteocytes or osteoblasts? This study indicates MLO-Y4 osteocyte-like cells show stronger response to 10 dynes $/ \mathrm{cm}^{2}$ oscillatory fluid flow shear stress than MC3T3-E1 osteoblast-like cells.

Cellular morphology determines cellular function, and is related to the organization of cellular cytoskeletal components. Klein-Nulend Jenneke et al have investigated the differences in morphology of osteocytes and their lacunae in long bones

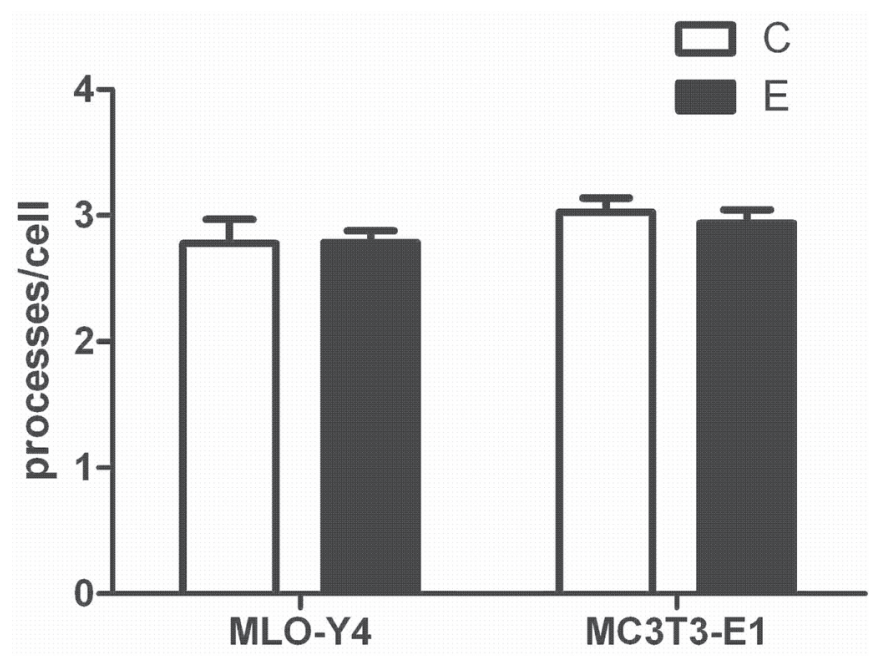

Fig. 2. The number of processes per cell was not influenced by $2 \mathrm{~h}$ of fluid flow stress in MLO-Y4 cells and MC3T3-E1 cells. The processes were observed under microscope $(\times 200)$ and counted using simple $\mathrm{PCl}$ software. C: control, E: $2 \mathrm{~h}$ of oscillatory fluid flow. with different bone mineral densities (BMD). It is believed that the morphological differences may reflect differences in mechanosensitivity and the adaptation to different external loading conditions (van Hove et al., 2009). In this study, fluid flow stimulation only increased the cell area of MLO-Y4 cells and not that of MC3T3-E1 cells, despite the fact that the size of MC3T3-E1 cells is larger than that of the MLO-Y4 cells and hence has a larger cell membrane area exposed to shear flow. Increasing cell area may improve adhesion of the cells to the extra cellular matrix (ECM) and improve their resistance to fluid flow stress. These morphological results suggest that osteocytes could respond more strongly than do osteoblasts to fluid shear stress.

Consistent with the results of Zhang et al, gene expression of E11/gp38 increased in both cell lines, but to a greater degree in MLO-Y4 (Zhang et al., 2006). Their studies have shown that an increase in mRNA of E11 is coupled with an elongation of dendrites after $2 \mathrm{~h}$ of fluid flow followed by $24 \mathrm{~h}$ of incubation in MLO-Y4 cells. Ponik et al found that after applying $24 \mathrm{~h}$ of OFF at $0.5 \mathrm{~Hz}, 11$ dynes $/ \mathrm{cm}^{2}, 44 \%$ of MLO-Y4 cells have more than 3 dendrites per cell, while in a static condition, only $31 \%$ of cells do (Ponik et al., 2007). In this study our results show that $2 \mathrm{~h}$ of OFF could increase the expression of E11/gp38, but it is not sufficient to induce new dendrite formation. Maybe a longer incubation time is necessary, like what was shown in Zhang et al's experiments (Zhang et al., 2006).

Our previous studies and those of other researchers have shown that cellular cytoskeleton of bone cells can rearrange to adapt to mechanical environments (Malone et al., 2007; McGarry et al., 2005; Ponik et al., 2007; Qian et al., 2010; Qian et al., 2012). Here, we demonstrated that fluid flow stress causes a remarkable increase in $\beta$-actin and $\alpha$-tubulin expression at mRNA level, and promotion in stress fiber formation in MLO-Y4 cells, not in MC3T3-E1 cells. As well, at protein level, $\alpha$-tubulin increased more in MLO-Y4 cells than in MC3T3-E1 cells. The different responses of cytoskeleton reorganization are possibly related to the different function and distribution of the cytoskeleton in MLO-Y4 and MC3T3-E1. Previous studies have shown that disruption of the actin cytoskeleton can block fluid flow-induced prostaglandin release in osteocytes (Ajubi et al., 1996; McGarry et al., 2005), but not in osteoblasts (McGarry et al., 2005). As well, our results show expression of $\beta$-actin protein increases equally in both cells, but stress fiber formation increases only in MLO-Y4 cells, not in MC3T3-E1 cells. Consequently, we presume the promotion of fiber stress in MLO-Y4 cells mainly comes from rearrangement of F-actin, not the expression of $\beta$-actin.

Integrin $\alpha v \beta 3$ is predominantly found in osteocytes compared to osteoblasts (Bennett et al., 2001). It also carries out signal transduction via a vinculin-involved focal adhesion complex (Samanna et al., 2006). One of its ligands (Chellaiah and Hruska, 2003; Miyauchi et al., 2006; Samanna et al., 2006), OPN, can interact with the cell surface receptor, CD44 (Chellaiah and Hruska, 2003; Weber et al., 1996), which also links ECM proteins and the cytoskeleton (Kang et al., 2008). Fluid flow induced OPN upregulation in MC3T3-E1 cells has also been found (Ponik et al., 2007; You et al., 2001). In osteocytes, OPN regulates the mechanical stress threshold by controlling the activity of ion channels in cellular membrane (Miyauchi et al., 2006). In our experiment, the expression of integrin-associated molecules, such as vinculin, OPN and CD44, all were upregulated in MLO-Y4 cells, but not in MC3T3-E1 cells, which shows integrin-associated pathway 
plays an important role in osteocytes' mechano-chemical signal response to $2 \mathrm{~h}$ of OFF. As well, these integrin-related molecules participate in the formation of focal adhesion complexes, which plays an important role in cell adhesion and signal transduction. Together with the increases of cell area and fiber stress formation in MLO-Y4 cells, we think osteocytes might response to $2 \mathrm{~h}$ of fluid flow shear stress through rearranging cytoskeleton structure, increasing cell adhesion with ECM, in turn increase the expression of integrin-related molecules to transfer mechanical signal into cells to regulate downstream signals.

Further investigation into the role of integrin-associated molecules in response to fluid flow and related changes of downstream intracellular signals will be carried out in the future.

In conclusion, it has been found that cell area, expression of cytoskeleton molecules, formation of fiber stress and expression of integrin-associated molecules were promoted in
MLO-Y4 cells, but not in MC3T3-E1 cells. These changes may be related to both cellular function of cell adhesion and signal transduction. MLO-Y4 osteocyte-like cells show a stronger response to $2 \mathrm{~h}$ of fluid flow shear stress than MC3T3-E1 osteoblast-like cells.

\section{ACKNOWLEDGEMENTS}

This work was supported by the Major State Basic Research Development Program of China (973 Program, 2011CB710903), National Natural Science Foundation of China (31170812 \& 30700152) and Northwestern Polytechnical University Foundation for Fundamental Research (NPU-FFR-JC201160). We would like to thank Prof. Lynda Bonewald (University of Missouri-Kansas City) for gifting the MLO-Y4 cell line. And we thank Yuchen Wang and April Dunham for revising this manuscript.
C
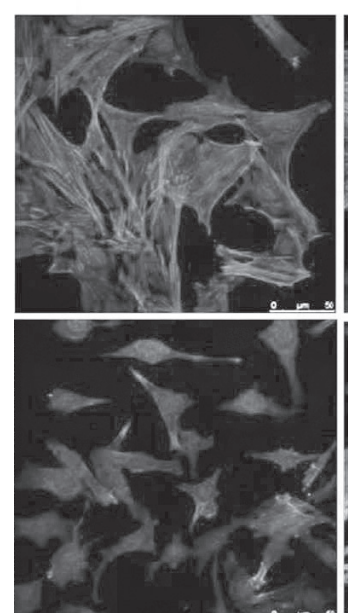

C
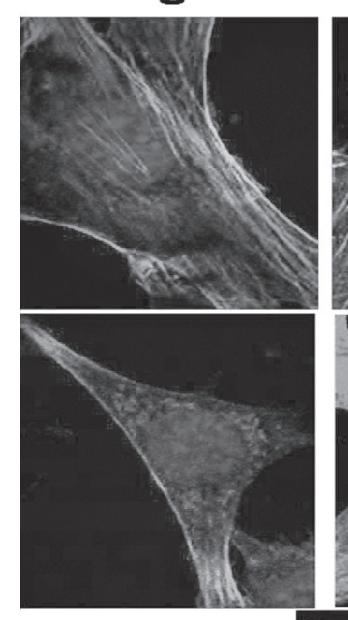

0
E
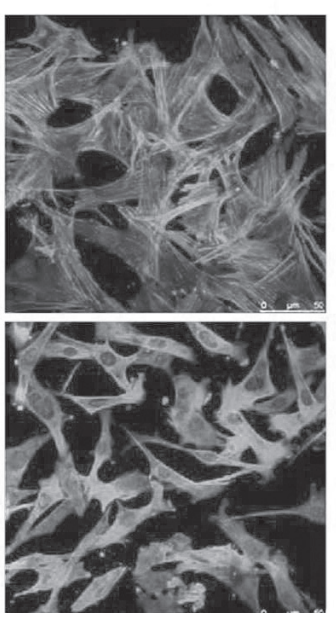

E

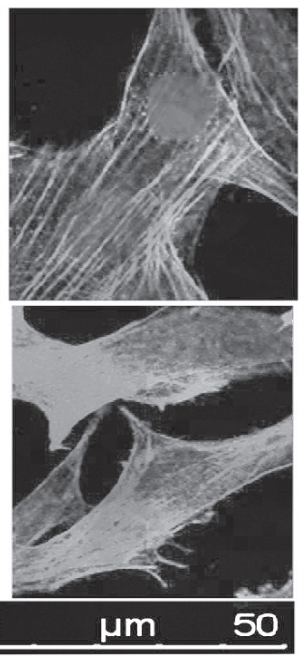

C
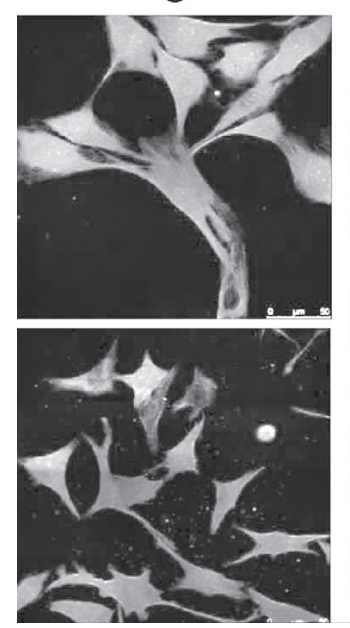

C
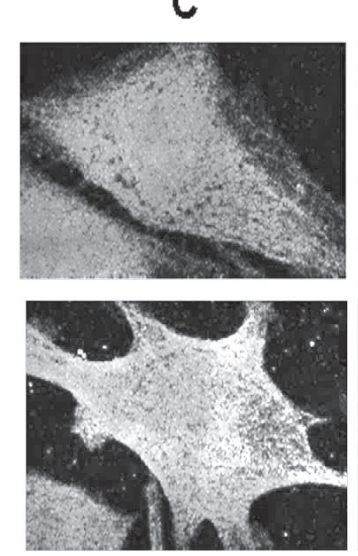

E

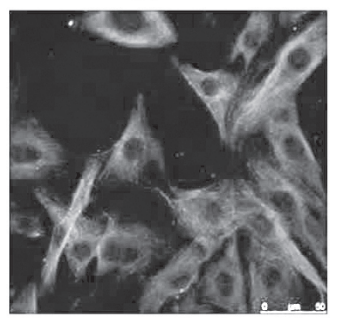

MC3T3-E1

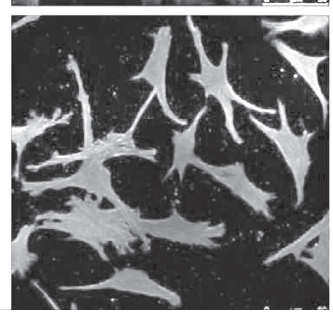

E

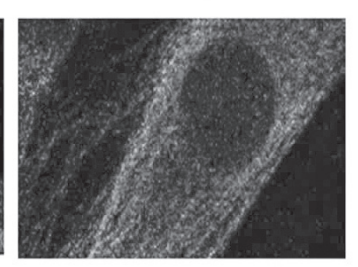

MC3T3-E1

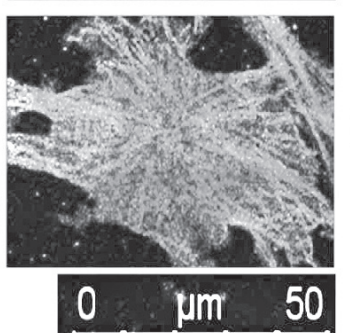

MLO-Y4

MLO-Y4

Fig. 3. After $2 \mathrm{~h}$ of OFF stimulation, expression of $\beta$-actin (a) and $\alpha$-tubulin (b), and stress fiber formation were clearly promoted in MLO-Y4 cells. On the other hand, in MC3T3-E1 cells, there was no clear difference compared to that of control. Cells were incubated by rhodamine labeled-phalloidin (1:40, Invitrogen) or antibody of $\alpha$-tubulin (1:2000, Sigma) overnight. Then cell were incubated for $1 \mathrm{~h}$ in FITC labeled $(1: 10, K P L)$ secondary antibody in order to stain the tubulin. After that, cells were washed using TBS with $0.1 \%$ Triton and sealed, then observed using confocal microscopy. (c) and (d) are the amplified images of (a) and (b). The bar is $50 \mu \mathrm{m}$. C: control, E: $2 \mathrm{~h}$ of oscillatory fluid flow. 


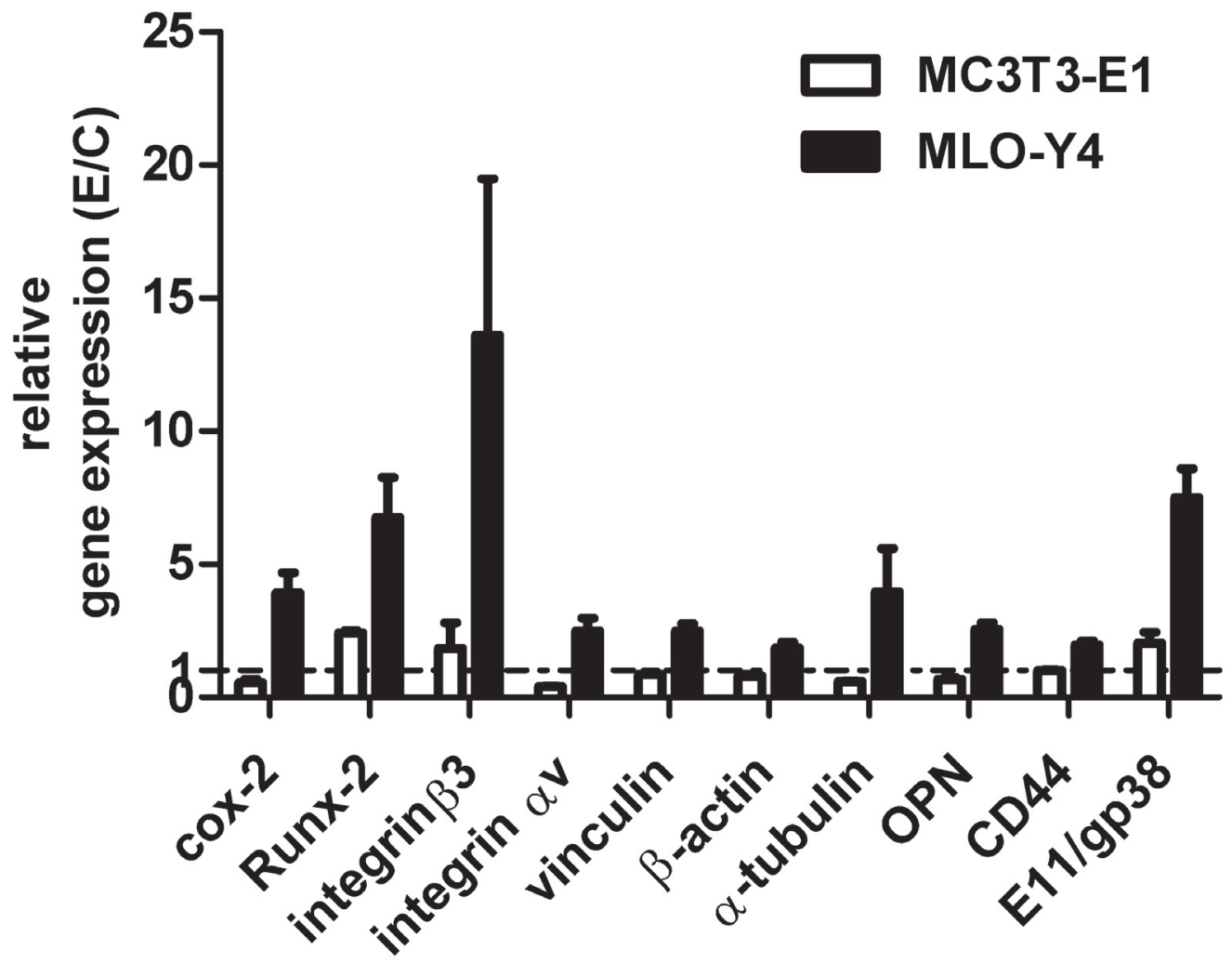

Fig. 4. Quantitative real-time PCR was carried out to detect gene expression at the mRNA level. The Livak method was used to estimate relative changes. After $2 \mathrm{~h}$ of OFF stimulation, expression of integrin-associated molecules were changed in the MLO-Y4 cells, while in MC3T3-E1 cells the change was not obvious.

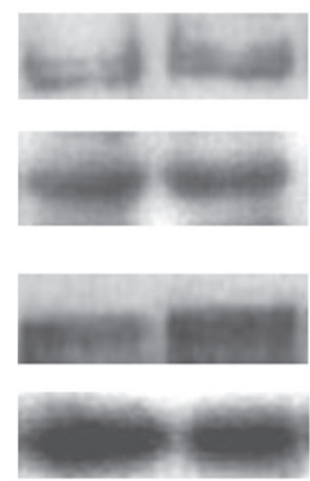

MLO-Y4

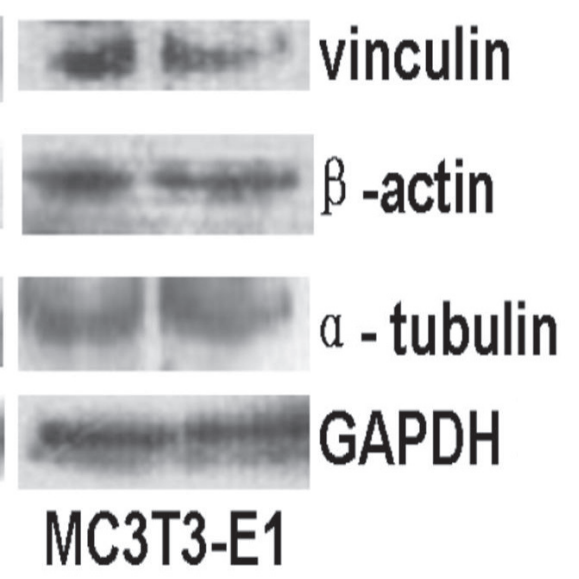

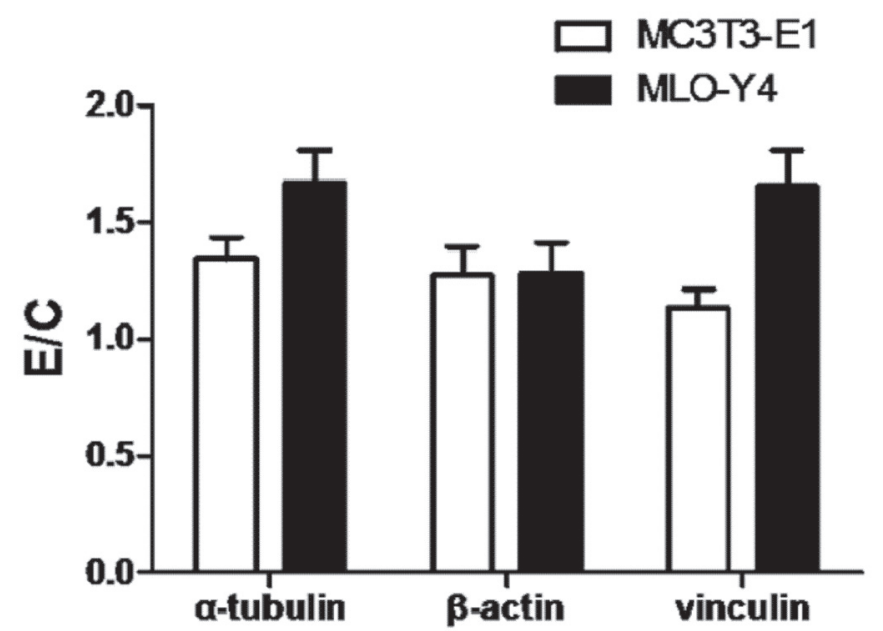

Fig. 5. Western blotting was carried out to detect gene expression at protein level. After $2 \mathrm{~h}$ of OFF stimulation, proteins was subjected to SDS-PAGE $(10 \%)$ and transferred to NC membranes. The blots were respectively probed with antibodies of $\beta$-actin (1:2000, Sigma) and $\alpha$-tubulin (1:1000, Calbiochem) and vinculin (1:1500, Sigma) detected by enhanced chemiluminescence. GAPDH (glyseraldehyde-3phosphate dehydrogenase, 1:2000, Calbiochem) was as the internal control protein. (b) is the statistic figure of three results. 


\section{REFERENCES}

AJUBI NE, KLEIN-NULEND J, NIJWEIDE PJ, VRIJHEID-LAMMERS T, ALBLAS MJ, BURGER EH, JIANG JX (1996) Pulsating fluid flow increases prostaglandin production by cultured chicken osteocytes--a cytoskeletondependent process. Biochem Biophys Res Commun 225:62-8.

ALENGHAT FJ, INGBER DE (2002) Mechanotransduction: all signals point to cytoskeleton, matrix, and integrins. Sci STKE 2002:6.

BARRON MJ, TSAI CJ, DONAHUE SW (2010) Mechanical stimulation mediates gene expression in MC3T3 osteoblastic cells differently in 2D and 3D environments. J Biomech Eng 132:041005.

BENNETT JH, CARTER DH, ALAVI AL, BERESFORD JN, WALSH S (2001) Patterns of integrin expression in a human mandibular explant model of osteoblast differentiation. Arch Oral Biol 46:229-238.

BONEWALD LF (1999) Establishment and characterization of an osteocytelike cell line, MLO-Y4. J Bone Miner Metab 17:61-5.

CHELLAIAH MA, HRUSKA KA (2003) The Integrin \{alpha\} $\{$ beta\} 3 and CD44 Regulate the Actions of Osteopontin on Osteoclast Motility. Calcified Tissue Int 72:197-205.

GEIGER B, BERSHADSKY A, PANKOV R, YAMADA KM (2001) Transmembrane crosstalk between the extracellular matrix--cytoskeleton crosstalk. Nat Rev Mol Cell Biol 2:793-805.

JACOBS CR, YELLOWLEY CE, DAVIS BR, ZHOU Z, CIMBALA JM, DONAHUE HJ (1998) Differential effect of steady versus oscillating flow on bone cells. J Biomech 31:969-976.

JIANG JX, CHENG B (2001) Mechanical stimulation of gap junctions in bone osteocytes is mediated by prostaglandin E2. Cell Commun Adhes 8:283-8.

KAMIOKA H, SUGAWARA Y, MURSHID SA, ISHIHARA Y, HONJO T, TAKANO-YAMAMOTO T (2006) Fluid shear stress induces less calcium response in a single primary osteocyte than in a single osteoblast: implication of different focal adhesion formation. J Bone Miner Res 21:1012-21.

KANG WS, CHOI JS, SHIN YJ, KIM HY, CHA JH, LEE JY, CHUN MH, LEE MY (2008) Differential regulation of osteopontin receptors, CD44 and the [alpha]v and [beta] 3 integrin subunits, in the rat hippocampus following transient forebrain ischemia. Brain Res 1228:208-216.

KLEIN-NULEND J, BURGER EH, SEMEINS CM, RAISZ LG, PILBEAM CC (1997) Pulsating fluid flow stimulates prostaglandin release and inducible prostaglandin $\mathrm{G} / \mathrm{H}$ synthase mRNA expression in primary mouse bone cells. J Bone Miner Res 12:45-51.

KLEIN-NULEND J, SEMEINS CM, AJUBI NE, NIJWEIDE PJ, BURGER EH, JIANG JX (1995) Pulsating fluid flow increases nitric oxide (NO) synthesis by osteocytes but not periosteal fibroblasts--correlation with prostaglandin upregulation. Biochem Biophys Res Commun 217:640-8.

LETECHIPIA JE, ALESSI A, RODRÍGUEZ G, ASBUN J (2010) Would increased interstitial fluid flow through in situ mechanical stimulation enhance bone remodeling? Medical Hypotheses 75:196-198.

LIVAK KJ, SCHMITTGEN TD (2001) Analysis of Relative Gene Expression Data Using Real-Time Quantitative PCR and the 2-[Delta][Delta]CT Method. Methods 25:402-408.

MALONE AMD, BATRA NN, SHIVARAM G, KWON RY, YOU L, KIM CH, RODRIGUEZ J, JAIR K, JACOBS CR (2007) The role of actin cytoskeleton in oscillatory fluid flow-induced signaling in MC3T3-E1 osteoblasts. Am J Physiol Cell Physiol 292:C1830-1836.

MCGARRY JG, KLEIN-NULEND J, PRENDERGAST PJ (2005) The effect of cytoskeletal disruption on pulsatile fluid flow-induced nitric oxide and prostaglandin E2 release in osteocytes and osteoblasts. Biochem Biophys Res Commun 330:341-8.
MIYAUCHI A, GOTOH M, KAMIOKA H, NOTOYA K, SEKIYA H, TAKAGI Y, YOSHIMOTO Y, ISHIKAWA H, CHIHARA K, TAKANOYAMAMOTO T, FUIITA T, MIKUNI-TAKAGAKI Y (2006) AlphaVbeta3 integrin ligands enhance volume-sensitive calcium influx in mechanically stretched osteocytes. J Bone Miner Metab 24:498-504.

MURSHID SA, KAMIOKA H, ISHIHARA Y, ANDO R, SUGAWARA Y, TAKANO-YAMAMOTO T (2007) Actin and microtubule cytoskeletons of the processes of 3D-cultured MC3T3-E1 cells and osteocytes. J Bone Miner Metab 25:151-158.

PONIK SM, TRIPLETT JW, PAVALKO FM (2007) Osteoblasts and osteocytes respond differently to oscillatory and unidirectional fluid flow profiles. J Cell Biochem 100:794-807.

QIAN A, YANG P, HU L, ZHANG W, DI S, WANG Z, GAO X, SHANG P (2010) High Magnetic Gradient Environment Causes Alterations of Cytoskeleton and Cytoskeleton Associated Genes in Human Osteoblasts Cultured in vitro. Adv Space Res 46:687-700.

OIAN AR, WANG L, GAO X, ZHANG W, HU LF, HAN J, LI JB, DI SM, SHANG P (2012) Diamagnetic Levitation Causes Changes in the Morphology, Cytoskeleton and Focal Adhesion Proteins in Osteocytes. IEEE Trans Biomed Eng 59:68-77.

REICH KM, FRANGOS JA (1993) Protein kinase C mediates flow-induced prostaglandin E2 production in osteoblasts. Calcif Tissue Int 52:62-6.

REILLY GC, HAUT TR, YELLOWLEY CE, DONAHUE HJ, JACOBS CR (2003) Fluid flow induced PGE2 release by bone cells is reduced by glycocalyx degradation whereas calcium signals are not. Biorheology 40:591-603.

SAMANNA V, WEI H, EGO-OSUALA D, CHELLAIAH MA (2006) Alpha-Vdependent outside-in signaling is required for the regulation of CD44 surface expression, MMP-2 secretion, and cell migration by osteopontin in human melanoma cells. Exp Cell Res 312:2214-2230.

SWAN CC, LAKES RS, BRAND RA, STEWART KJ (2003) Micromechanically based poroelastic modeling of fluid flow in Haversian bone. J Biomech Eng 125:25-37

VAN HOVE RP, NOLTE PA, VATSA A, SEMEINS CM, SALMON PL, SMIT TH, KLEIN-NULEND J (2009) Osteocyte morphology in human tibiae of different bone pathologies with different bone mineral density -- Is there a role for mechanosensing? Bone 45:321-329.

VATSA A, BREULS RG, SEMEINS CM, SALMON PL, SMIT TH, KLEINNULEND J (2008) Osteocyte morphology in fibula and calvaria -- Is there a role for mechanosensing? Bone 43:452-458.

WEBER GF, ASHKAR S, GLIMCHER MJ, CANTOR H (1996) Receptor-ligand interaction between CD44 and osteopontin (Eta-1). Science 271:509-12.

WEINBAUM S, COWIN SC, ZENG Y (1994) A model for the excitation of osteocytes by mechanical loading-induced bone fluid shear stresses. J Biomech 27:339-360.

WESTBROEK I, AJUBI NE, ALBLAS MJ, SEMEINS CM, KLEIN-NULEND J, BURGER EH, NIJWEIDE PJ, JIANG JX (2000) Differential stimulation of prostaglandin G/H synthase-2 in osteocytes and other osteogenic cells by pulsating fluid flow. Biochem Biophys Res Commun 268:414-9.

YOU J, REILLY GC, ZHEN X, YELLOWLEY CE, CHEN Q, DONAHUE HJ, JACOBS CR (2001) Osteopontin Gene Regulation by Oscillatory Fluid Flow via Intracellular Calcium Mobilization and Activation of Mitogen-activated Protein Kinase in MC3T3-E1 Osteoblasts. J Biol Chem 276:13365-13371.

ZHANG K, BARRAGAN-ADJEMIAN C, YE L, KOTHA S, DALLAS M, LU Y, ZHAO S, HARRIS M, HARRIS SE, FENG JQ, BONEWALD LF (2006) E11/gp38 Selective Expression in Osteocytes: Regulation by Mechanical Strain and Role in Dendrite Elongation. Mol Cell Biol 26:4539-4552. 
